доктор философских наук, профессор, профессор кафедры общетеоретических правовых дисциплин

Северо-Кавказского филиала Российского государственного университета правосудия

\section{РОЛЬ И МЕСТО ЕСТЕСТВЕННОГО ПРАВОПОНИМАНИЯ В ИНТЕГРАТИВНОМ ПОДХОДЕ К ПРАВУ}

\section{Аннотация:}

В статье рассматриваются естественное и позитивное правопонимание в контексте преодоления их одностороннего подхода через синтез уже имеющегося знания. Автор статьи анализирует особенности естественного правопонимания с точки зрения возникающей в процессе исторического развития потребности и возможности позитивации естественного права, а также разделяет точку зрения О. Хёфффе об объективно существующей связи между позитивным правом и позитивной моралью. В статье отмечается неантогонистический характер противоречий между сложившимися типами представлений о существе права. Автор также подчеркивает перспективность интегративной методологии и ее актуальность при достижении сложившимися классическими типами взглядов на сущность права такого уровня развития, при котором возникает осознанная потребность 6 синтезе имеющихся односторонних точек зрения.

Ключевые слова:

право, синтез, правопонимание, общество, синте тическая теория права, синтетическая методология, философия права.
D.Phil., Professor, General Theoretical and Legal Department, North Caucasus branch of Russian State University of Justice

\section{ROLE AND PLACE OF NATURAL LEGAL THINKING IN INTEGRATIVE APPROACH TO LAW}

Keywords: law, synthesis, legal thinking, society, synthetic theory

of law, synthetic methods, philosophy of law.

Natural and positive legal thinking is considered in the context of overcoming its unilateral approach to law through the synthesis of the knowledge available. The author analyzes the features of natural legal thinking in terms of the requirement arising in the course of the historical development and the possibility of natural law to become positive. Besides, the researcher supports a view of 0 . Höffe on objectively existing relationships between positive law and positive morals. The paper notes the non-antagonistic nature of contradictions between different interpretations of the substance of law. In addition, the author emphasizes the prospects and relevance of integrative methods when the established views on the essence of law are sufficiently developed, and there is a need for the synthesis of the available unilateral opinions on the law.

Вопросы, касающиеся различных аспектов правопонимания, а тем более перспектив его развития, всегда будут в числе актуальных и сложных. Трудно не согласиться с Б.А. Кистяковским, слова которого не теряют своей остроты и сегодня: «Ни в какой другой науке нет столько противоречащих друг другу теорий, как в науке о праве. При первом знакомстве с нею получается даже такое впечатление, как будто она только и состоит из теорий, взаимно исключающих друг друга» [1, с. 374]. Такое положение дел объясняется рядом причин объективного и субъективного характера. Особую остроту в истории правовой мысли обрело противостояние естественного правопонимания и юридического позитивизма.

Естественное правопонимание, если рассматривать его с точки зрения теории и истории права, занимает свое, уже давно отведенное ему место, связанное с общей идеей права, основывающейся на нравственных представлениях людей. Это не означает подмену права нравственностью, а лишь указывает на то, что право не может не считаться с нравственными целями общества, препятствовать их достижению. Но в истории полемики между представителями естественного правопонимания и юридического позитивизма вопрос о нравственной природе права всегда был одним из самых дискуссионных. Так, например, Г.Ф. Шершеневич, вступая в полемику со сторонниками естественного права, задавался вопросом о том, каким образом право, являясь нравственностью, тем не менее лежит в совершенно иной плоскости, чем она. Он отмечал неоднозначность взаимосвязи права и нравственности, так как право может в одном случае опережать, в других случаях - совпадать с ней или вообще не иметь с нравственностью ничего общего. Г.Ф. Шершеневич полагал, что встречающееся совпадение юридических и нравственных норм объясняется тождеством их целей, а несовпадение - различием средств их поддержания. С позиций юридического позитивизма Г.Ф. Шершеневич в своей работе «Общая теория права» утверждал следующее: «Подчеркивая социальный характер всех норм нравственности, мы имеем в виду не то, что нравственное сознание индивида образовалось под влиянием общественной среды, может быть, путем 
восприятия чужих нравственных переживаний, а то, что нравственное поведение обусловливается социальным авторитетом. Нормы нравственности - это требования, обращенные к человеку извне. Нравственный закон не в нас, а вне нас, как и звездное небо» [2, с. 184].

Противоречия между сторонниками естественного правопонимания и позитивистами возникали и по другим вопросам, однако, как подчеркивает известный немецкий ученый О. Хёфффе, неверно толковать отношение между этими типами правопонимания как антагонистические. На самом деле, в отношениях между естественным правом и юридическим позитивизмом существуют взаимозависимость и взаимодополняемость, которые свидетельствуют о том, что имеющиеся противоречия носят неантагонистический характер. Такой методологический подход позволяет говорить о естественно-правовом и позитивистском типах правопонимания как взаимосвязанных элементах системы интегративного восприятия права. Однако для такого понимания требуется определенное время. И совершенно верно В.В. Лазарев отмечает влияние уровня развития правовой идеи на понимание непротиворечивого характера взаимоотношения между разными типами правопонимания: «Впрочем, и нормативистская, и естественно-правовая позиции, при надлежащем их развитии, также способны к взаимопониманию, если исключить ортодоксов той и другой, если изначально не претендовать на создание единственно верной научной концепции объяснения окружающей действительности» [3, с. 26].

История эволюции типов правопонимания свидетельствует о неизбежных изменениях взглядов их сторонников, которые происходят под влиянием конкретных исторических условий и развития человечества в целом. Со временем более рельефными становятся как недостатки различных подходов к праву, так и действительно присущие ему характеристики. Становится очевидной необходимость преодоления односторонности и абсолютизации отдельных аспектов права в правовых теориях, и остро осознается потребность его целостного восприятия посредством синтеза (интеграции) уже имеющегося знания. В то же время очень важно находить точки соприкосновения между разными типами правопонимания. Совершенно верно В.Н. Корнев отметил, что «...вряд ли будет оправданной и конструктивной критика подобных монистических теорий, ведущаяся с иных методологических позиций, чем те, на которых выстраиваются подобные теории. Противопоставление различных методологических подходов к пониманию и познанию права, а тем более вынесение приговоров, например, юридическому позитивизму, не будет способствовать формированию научных представлений о действующем объективном праве» [4, с. 22].

Сегодня вряд ли кто-то станет утверждать, что позитивистский подход полностью отрицает связь права и нравственности. Этическое основание правовых отношений явно находит, например, свое проявление при осуществлении субъективных гражданских прав. Участники регулируемых гражданским законодательством правоотношений обязаны уважать моральные принципы и нравственные нормы общества при осуществлении своих прав, что закреплено в статьях Гражданского кодекса. В юридических текстах закрепляются также и такие нравственные по своему содержанию понятия, как «добрые нравы», «добросовестность», «разумность», «справедливость» и т. д.

Нравственную обусловленность имеет и уголовно-правовая норма, что выражается на стадии как конструирования нормы, так и ее применения и усовершенствования. Нравственная обусловленность уголовно-правовой нормы проявляется в задачах и принципах уголовного права, в целях наказания, в поощрительных и стимулирующих нормах и т. д. Иными словами, нравственная природа права может рассматриваться как неотъемлемая характеристика, которая должна быть включена в интегративное правопонимание.

Свой путь к осознанию динамики наших представлений о праве проходит и естественное правопонимание. Безусловно, естественное право привносит в правовую сферу жизни общества и личности надпозитивные принципы, связанные с понятиями справедливости, критической оценки волеустановленного права, ценностного подхода к праву и т. д. В своем развитии концепция естественного правопонимания прошла несколько этапов. Они способствовали ее становлению в аспекте разработки естественных прав человека, механизма их обоснования, позитивации естественного права.

В то же время естественное право несет в себе угрозу субъективистского критицизма относительно сложившегося правопорядка и системы законодательства. Несмотря на свой гуманизм, духовно-нравственную основу, естественно-правовой тип правопонимания не может подменить собой позитивистский подход с его мощным потенциалом поддержания правопорядка. Иными словами, сложившиеся монистические типы правопонимания объективно ограничены в своем видении и имеют недостатки, которые снижают их гносеологическую и практическую ценность.

Если посмотреть на естественное правопонимание с точки зрения интегративного подхода, то становится очевидным его необходимое присутствие в синтезе (интеграции) различных подходов к праву. Так называемое противоречие между естественным и позитивным правом снимается в интегративном подходе, который соединяет различные, противоречивые на первый взгляд элементы, единство которых обусловлено самой природой права, не сводимой к какой-либо одной его характеристике. 
Подтверждением того, что интегративный подход, претендующий на целостное и системное знание, должен включать в качестве необходимых элементов естественное и позитивистское правопонимания, является, с одной стороны, стремлением естественного права к позитивации и легитимации естественных прав человека и нравственной составляющей правовых отношений; с другой стороны - потребностью позитивного права в позитивной морали, которая опирается на сложившиеся в человеческом обществе нравы и обычаи.

Также важно отметить, что интегративный подход позволяет отказаться от тех положений в существующих типах правопонимания, которые не отвечают объективно единой природе права. Через интегративный подход происходит «отбор» тех характеристик права, которые отражают его системность и единство в многообразии.

Таким образом, тенденции развития естественного и позитивного права свидетельствуют о том, что наступает этап, когда противоречия перестают быть антагонистическими. Это делает возможной постановку вопроса о синтезе (интеграции) разных взглядов на сущность права. В этом контексте можно говорить о том, что формирование интегративного подхода - это индикатор достижения такого уровня, который свидетельствует, что в развитии традиционных типов правопонимания на первый план выходит не борьба, а осознанное единство. Иными словами, через призму интегративного подхода естественно-правовая мысль, например, видит не только воплощение принципа справедливости, но и фактическую силу, которую право получает от законодателя. При этом не допускается мысль о произволе государства, сохраняется рациональнокритическая оценка волеустановленного права.

Следует подчеркнуть, что и юридический позитивизм в своем развитии приходит к пониманию важности для современного человека тех основ, на которые опирается естественное право. Однако при этом происходит позитивно-властное закрепление представлений законодателя о справедливости, формальном равенстве и пр.

Иными словами, формирование интегративного подхода говорит о возможности совместить разные, в данном случае естественно-правовой и позитивистский подходы, не поступаясь их основополагающими принципами, но восполняя недостатки каждой из концепций, порождаемые односторонним взглядом на право как многогранный объект исследования.

В отечественном наследии уже были попытки обоснования методологического плюрализма, цель которых - отображение объективно существующего многообразия свойств права. В этом контексте весьма интересна и не теряет своей актуальности работа И.А. Ильина «Понятие права и силы. Опыт методологического анализа», в которой автор пытается выделить общее и особенное в познании права с юридической и неюридической точек зрения через призму вопроса о соотнесенности права и силы. Он называет свой подход методологическим плюрализмом. Ценность такого подхода, включающего как юридический, так и неюридический (психологический, социологический, политический и т. д.) взгляд на сущность права и соотносимых с ним понятий, позволяет обеспечить общий и всесторонний познавательный анализ.

Юридический подход, подчеркивает И.А. Ильин, - это отождествление его исключительно с нормой и суждением. Однако психологический и социологический подходы тоже не отрицают нормативности права. Но при этом психологический подход рассматривает правовую норму как переживаемую норму, а социологический - как «норму, введенную через применение ее в фактический состав общественных отношений в качестве схемы этих отношений» [5, с. 199]. Такие взгляды не являются ошибочными, так как соответствуют тем методам, которые применялись к праву.

Рассуждая о необходимости и возможности интегративного подхода при существовании многообразия концепций, очень важно помнить о наличии объединяющего начала в интегративном процессе, так как оно помогает избежать бессистемного и механического соединения имеющихся точек зрения в правовой науке. В свое время А.С. Ященко, посвятивший свои труды разработке синтетической точки зрения на право, предостерегал исследователей от внешнего эклектизма, т. е. механического соединения различных принципов и элементов. Он подчеркивал необходимость «для настоящего жизненного синтеза органического соединения всех односторонних определений на основании синтезирующей силы всеобъемлющего начала, являющегося живой душой всего соединения» [6, с. 58].

Завершить рассуждения о методологических вопросах правопонимания хотелось бы словами Б.А. Кистяковского, который, хотя и не оставил нам конкретной концепции на плюралистическом основании, внес свой заметный вклад в предпосылки становления современного правосознания и правопонимания. «Право как явление, - писал Б.А. Кистяковской, - несмотря на свое многообразие, едино. Поэтому и общая теория права нуждается в фрормах познания права, более полно и всесторонне объединяющих познанное. Иначе говоря, необходим синтез всего знания о праве... Результатом этого синтетического познания права должно быть не определение какогото нового понятия права, а раскрытие и постижение смысла права» [7, с. 678]. 


\section{Ссылки:}

1. Кистяковский Б.А. Социальные науки и право. Очерки по методологии социальных наук и общей теории права. М., 1916. С. 374.

2. Шершеневич Г.Ф. Общая теория права : в 2 т. М., 1910.

3. Lazarev V. Integrative perception of law // Kazan University Law Review. 2016. Vol. 1, no. 1. P. 19-32.

4. Корнев В.Н. Монистические и интегративные (синтетические) теории обоснования природы государства и права // Российское правосудие. 2017. № 5 (133). С. 19-28.

5. Ильин И.А. Теория права и государства. 2-е изд., доп. М., 2008.

6. Ященко А.С. Философия права Владимира Соловьева. Теория федерализма. СПб., 1999. 254 с.

7. Кистяковский Б.А. Указ соч. С. 678.

\section{References:}

Ilyin, IA 2008, Theory of law and state, 2nd ed., Moscow, (in Russian)

Kistyakovsky, BA 1916, Social sciences and law. Essays on the methods of social sciences and general theory of law, Moscow, pp. 374, 678, (in Russian)

Kornev, VN 2017, 'Monistic and Integrative (Synthetic) Theories of Nature of State and Law Substantiation', Russian Justice, no. 5 (133), pp. 19-28. https://doi.org/10.17238/issn2072-909x.2017.5.19-28.

Lazarev, V 2016, 'Integrative perception of law', Kazan University Law Review, vol. 1, no. 1, pp. 19-32.

Shershenevich, GF 1910, General theory of law, in 2 vols., Moscow, (in Russian).

Yaschenko, AS 1999, Philosophy of law by Vladimir Solovyov. The theory of federalism, St. Petersburg, 254 p., (in Russian). 